\title{
Are Psychiatric Diagnoses an Obstacle for Research and Practice? Reliability, Validity and the Problem of Psychiatric Diagnoses. The Case of GAD
}

\author{
Carlo Faravelli $^{\mathrm{a}, *}$, Giovanni Castellini ${ }^{\mathrm{b}}$, Monica Landi ${ }^{\mathrm{b}}$ and Andrea Brugnera ${ }^{\mathrm{a}}$ \\ ${ }^{a}$ Department of Psychology, University of Florence, Italy \\ ${ }^{b}$ Psychiatric Unit, Department of Neuropsychiatric Sciences, Florence University School of Medicine, Italy
}

\begin{abstract}
The present article focused on the problem of validity, reliability and specificity of psychiatric diagnoses.
The authors moved by the concept of syndrome, defined by Sydenham in the 18th century as a constellation of several interrelated symptoms, showing a stable, characteristic structure and a peculiar prognosis, in order to analyse the peculiarity of the current psychiatric nosology. In our opinion, the current nosographic system based on DSM-IV criteria, prevents psychiatry from benefiting of the significant technological progress that has led the rest of medical sciences to important clinical achievements in the last 20 years. The case of Generalized Anxiety Disorder was taken as an example of a disease characterized by unstable diagnostic criteria, high rate of comorbidity and uncertain boundaries. An analysis of the data from the Sesto Fiorentino study was performed to investigate the presence of common mood and anxiety symptoms across the most represented DSM IV diagnoses, in order to evaluate the specificity of these symptoms.
\end{abstract}

The results supported the hypothesis of a low specificity of these symptoms, suggesting the need for psychiatry to find new and more specific markers and instruments.

Keywords: Comorbidity, classification, diagnosis, synrome, symptoms.

\section{THE CONCEPT OF SYNDROME IN PSYCHIATRY}

The concept of syndrome is relatively recent. Most of the schools of medicine of the ancient world considered every single symptom and sign as a separate disease itself [1]. In 1742 , Sydenham was the first scientist to clearly formulate the minimum requirements needed to define a clinical condition as a syndrome. In his definition, a syndrome consists of several interrelated symptoms showing a stable, characteristic structure and a peculiar prognosis [2]. Furthermore, patients affected by a specific syndrome should share a sufficiently pathognomonic cluster of symptoms that allows clinicians to distinguish them from other patients suffering from different syndromes. Such fundamental elements of discontinuity among various syndromes were, at first, better conceptualized by Sneath [3], who introduced the term of "point of rarity" to refer to precise clinical boundaries among disorders, and were later revised by Kendell and Jablensky [4], who preferred the concept of "zone of rarity" separating psychiatric syndromes. The idea was that if a syndrome corresponds to a natural entity, than we should find a natural boundary or a discontinuity between this condition and its clinical "neighbours" [5]; in other terms, mixed conditions can exist, but they have to be less common than the pure syndromal form.

\footnotetext{
*Address correspondence to this author at the Department of Psychology, University of Florence. Via di San Salvi, 12 - Pad. 26 - 50135 Firenze, Italy; Tel; 055 4298447; Fax: 055 4298424; E-mail: carlo.faravelli@unifi.it
}

Several authors [i.e. 1, 2, 6] have investigated whether such a theoretical construct could be applied to the field of mental disorders. In spite of the improvement in this field, the validity of the actual classifications (ICD-10 [7], DSMIV-TR [8]) still remains a matter of debate. Although formal criteria to establish the validity of psychiatric diagnoses have been progressively proposed (i.e., descriptive features, sociodemographic factors, laboratory markers, exclusion criteria, neurobiologic and genetic validators, prognostic characteristics, level of functional and social disability, response to therapy, statistical deviation from the healthy condition, etc.) [9-11], in a clinical framework some of the conditions that are currently classified as psychiatric disorders still appear as vague and confusing (rather than discrete) entities. In particular, most of them show weak diagnostic criteria (low association between diagnostic symptoms and actual diagnosis), unspecific manifestations (poorly pathognomonic symptoms), and widespread onset (high comorbidity).

\section{AN EXAMPLE OF THE UNSTABLE DIAGNOSTIC CRITERIA IN PSYCHIATRY: THE GENERALIZED ANXIETY DISORDER}

According to the mentioned Sydenham's definition of syndrome, a first anomaly has to be taken into account: several diagnostic categories changed their criteria in different DSM editions and some of them were abolished, merged with other conditions, or divided into two or more entities. GAD was first introduced as a unique diagnosis in the third edition of the DSM (DSM-III) [12], but it was most often used as a residual diagnosis for individuals who did not meet 
diagnostic criteria for another anxiety disorder [13]. Considering the difficulty to discriminate between GAD and other disorders [14-15], the definition of GAD and the associated symptoms were substantially revised in the further edition of DSM. As a consequence, the DSM-IV-TR [8] considered GAD as an independent diagnosis among the anxiety disorders, characterized by "excessive, uncontrollable worry about a variety of topics that occurs more days than not for a period of at least six months". The worry causes distress and/or functional impairment, and is associated with at least three of the following features: restlessness or feeling keyed up or on edge, being easily fatigued, difficulty concentrating or mind going blank, irritability, muscle tension, and sleep disturbance (difficulty falling or staying asleep, or restless unsatisfying sleep) [8]. Indeed, four out of the six associated physical symptoms of GAD (i.e. restlessness, fatigue, difficulty concentrating, sleep difficulties, obsessive rumination, somatization) are also part of the diagnostic criteria for Major Depressive Disorder [16, 17]. Furthermore, symptoms required for GAD diagnosis are also present in other anxiety disorders, as closer overlaps probably exist between GAD and Panic Disorder or Social Anxiety Disorder [18].

In general the nosographic ambiguity - which is related to different psychiatric diagnoses - makes it very hard to define a stable constellation of interrelating symptoms and to characterize a specific population of patients with a specific diagnosis. The uncertain psychopathologic boundary of many psychiatric conditions seems to further move these disorders away from the original definition of discrete syndromes.

\section{THE PROBLEM OF COMORBIDITY}

The psychiatric comorbidity - defined as co-occurrence of two or more psychiatric diagnoses in the same patient raised a significant concern in the debate on the categorization of psychiatric disorders. The concept of comorbidity was first introduced by Feinstein [19] to denote those cases in which a 'distinct additional clinical entity' occurred during the clinical course of a patient having an index disease. This concept was recently used to indicate not only those cases in which a patient receives both a psychiatric and a general medical diagnosis, but also those cases in which two or more psychiatric diagnoses are present in the same patient [20]. The lack of well-defined and specific symptoms for many disorders and the high rates of GAD comorbidity with other anxiety and mood disorders make it difficult for the clinician to perform a reliable differential diagnosis and to correctly identify this condition [18,21]. Moreover, neurotic symptoms appear to be more frequent in mixed or associated forms than as parts of pure conditions. Again, the high rate for GAD comorbidity was considered to challenge the validity of this diagnosis. The different revisions of DSM criteria for GAD did not solve the matter of comorbidity, and its high rates of co-occurrence with other anxiety or mood disorder are still widely reported [13, 22-27].

\section{SYMPTOMS OVERLAP: EXPERIMENTAL DATA FROM THE SESTO FIORENTINO STUDY}

To support the concerns raised above, we performed further analyses of the data from the Sesto Fiorentino Study, a large community study, which has been described in detail elsewhere [28]. The main feature of this study is that psychi-

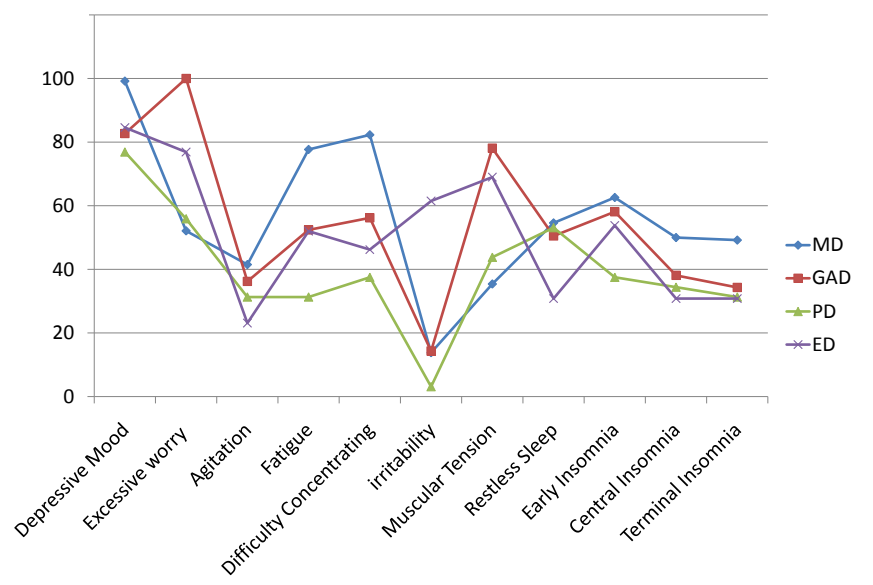

Fig. (1). Occurrence of specific symptoms across different diagnoses.

Vertical Axis reports percentage of occurrence of the symptoms according to different diagnoses.

atric symptoms are assessed "bottom up", i.e. regardless of the diagnosis: diagnostic categories are built up later, by computerized algorithms. There are several advantages of focusing on symptoms rather than diagnoses. Such an approach does not depend on pre-constructed nosological theories, allows the analysis of natural aggregations of symptoms even below their diagnostic cutoff points [29], permits the comparison of the qualitative and quantitative aspects [30], and can be useful to investigate specificity of diagnostic symptoms.

We evaluated the presence of some common mood and anxiety symptoms across the most represented DSM IV diagnoses (Fig. 1). It is clear that these symptoms occur transversally in a variety of diagnostic categories, with little variations from each other. As far as the GAD symptoms are concerned, a further analysis was performed on the data from the Sesto Fiorentino study: we tested for significant differences in each of the GAD symptom reported in Fig. (1), across diagnostic categories. This analysis generally confirmed the lack of specificity of the reported symptoms.

These results confirmed that the symptoms which are required for a diagnosis of Major Depressive Episode or Generalized Anxiety Disorder are essentially non-specific.

Moreover, symptoms tend to be considered as "stand alone", independently of the presence of other symptoms, whereas in the clinical practice the co-occurrence of other symptoms may consistently modify the interpretation of the clinical presentation. Suicidal thoughts accompanied by delusions of guilt are considered potentially more dangerous than suicidal ideation plus hystrionic features.

The application of the categorical model in psychiatry is likely to be different from the one used in other medical sciences. In general medicine, symptoms are considered either non-specific (fever or fatigue may be taken as an example), or specific (such as the aspect of blisters in HZV infection). In medicine we do not count symptoms in order to make a diagnosis: peritonitis and flu may share some symptoms, for example fever, pallor or fatigue (non-specific), but they cannot be used to make up the diagnosis of peritonitis with a comorbid flu, and in any case if a peritonitis is present, none 
would assign the same value to the symptom "fatigue" and to the one "abdominal guarding exacerbated by moving peritoneum".

DSM-III and its successors, became universally and uncritically accepted as the ultimate authority on psychopathology and diagnosis. DSM forms the basis for psychiatric teaching to both residents and undergraduates. Although it represents an undoubted progress for reliability and communication between clinicians and researchers, the price that psychiatry had to pay for these benefits is very high: the diagnostic process lost out in terms of sophistication and specificity.

According to Andreasen [30], our data demonstrated that diagnostic criteria include only some characteristic symptoms of a given disorder but they were never intended to provide a comprehensive description.

Validity has been sacrificed to achieve reliability. DSM diagnoses have given researchers a common nomenclature but probably the wrong one. Although creating standardized diagnoses that would facilitate research was a major goal, DSM diagnoses are not useful for research because of their lack of validity. Since the core features of mental illness were mainly unknown, both the symptom pattern and the prognostic value (e.g. duration, course and severity) of psychiatric syndromes were defined arbitrarily and conventionally. Many examples can be mentioned to support this idea, ranging from the scarce agreement between DSM/ICD classification systems $[31,32]$ to the lack of validity of schizophrenia subtypes [33] and the problems inherent in the diagnosis of some psychiatric disorders (i.e. schizoaffective disorder) $[34,35]$. Therefore, the validity of the present nosology has never been sufficiently demonstrated. On the contrary, the premise that original DSM diagnostic categories are primarily artificial and have no confirmed value of elementary clinical entities, is usually forgotten. This shortness of memory can push psychiatrists to think that DSM/ICD diagnoses are natural categorical entities (a phenomenon that Van Praag called "nosologomania"), thus making them accept unconditionally and uncritically the current classification system and ignore alternative models [36]. Many authors believe that this might represent a rather blind approach that may be either dangerous or useless in terms of application in biological and psychopharmacological research. In fact, most of the available scientific studies are actually based on the current arbitrary classification, even if it may not match with the correspondent biological and clinical sources. On the other hand, studies based on the socalled dimensional approach to psychopathology [37-39] show a relative aspecificity of diagnostic categories and provide robust examples of usefulness of reasoning, in terms of symptom clusters.

In our opinion, the current nosographic system prevents psychiatry from benefiting of the significant technological progress that has led the rest of medical sciences to important clinical achievements in the last 20 years. In the future, psychiatry will be probably able to find new and more specific markers and instruments [40, 41].
ABBREVIATIONS

$\begin{array}{lll}\mathrm{MD} & =\text { Major Depression } \\ \mathrm{GAD} & =\text { Generalized Anxiety Disorder } \\ \mathrm{PD} & =\text { Panic Disorder } \\ \mathrm{ED} & =\text { Eating Disorder }\end{array}$

\section{CONFLICT OF INTEREST}

None declared.

\section{ACKNOWLEDGEMENT}

None declared

\section{REFERENCES}

[1] Kendell RE. The concept of disease and its implications for psychiatry. Br J Psychiatry 1975; 127: 305-15.

[2] Häfner H. The concept of disease in psychiatry. Psychol Med 1987; 17(1): 11-4.

[3] Sneath PH. Some thoughts on bacterial classification. J Gen Microbiol 1957; 17: 184-200.

[4] Kendell R, Jablensky A. Distinguishing between the validity and utility of psychiatric diagnoses. Am J Psychiatry 2003; 160(1): 412.

[5] Kendell RE, Brockington IF. The identification of disease entities and the relationship between schizophrenic and affective psychoses. Br J Psychiatry 1980; 137: 324-31.

[6] Wakefield JC. The concept of mental disorder. On the boundary between biological facts and social values. Am Psychol 1992; 47: 373-88.

[7] World Health Organisation. ICD-10 Classifications of mental and behavioural disorders: clinical descriptions and diagnostic guidelines. Geneva; 1992.

[8] American Psychiatric Association. Diagnostic and Statistical Manual of Mental Disorder, 4th ed. APA, Washington DC; 2000.

[9] Robins E, Guze SB. Establishment of diagnostic validity in psychiatric illness: its application to schizophrenia. Am J Psychiatry 1970; 126: 983-7.

[10] Kendler KS. The nosologic validity of paranoia (simple delusional disorder): a review. Arch Gen Psychiatry 1980; 37: 699-706.

[11] Andreasen NC. The validation of psychiatric diagnosis: new models and approaches (editorial). Am J Psychiatry 1995; 152: 161-2.

[12] American Psychiatric Association. Diagnostic and Statistical Manual of Mental Disorder, 3rd ed. APA, Washington DC; 1980.

[13] Brown TA, Marten PA, Barlow DH. Discriminant validity of the symptoms constituting the DSM III-R and DSM IV associated symptom criterion of generalized anxiety disorder. J Anxiety Dis 995; 9: 317-28.

[14] Marten PA, Brown TA, Barlow DH, Borkovec TD, Shear MK, Lydiard RB. Evaluation of the ratings comprising the associated symptom criterion of DSM-III-R generalized anxiety disorder. J Nerv Ment Dis 1993; 181: 676-82.

[15] Brown TA, Barlow DH. A Proposal for a Dimensional Classification System Based on the Shared Features of the DSM-IV Anxiety and Mood Disorders: Implications for Assessment and Treatment. Psychol Assess 2009; 21: 256-71.

[16] Mennin DS, Heimberg RG, Fresco DM, Ritter MR. Is generalized anxiety disorder an anxiety or mood disorder? Considering multiple factors as we ponder the fate of GAD. Depress Anxiety 2008; 25: 289-99.

[17] Sunderland M, Mewton L, Slade T, Baillie A. Investigating differential symptom profiles in major depressive episode with and without generalized anxiety disorder: true co-morbidity or symptom similarity? J Psychol Med 2010; 40: 1113-23.

[18] Rickels K, Rynn MA. What is generalized anxiety disorder? J Clin Psychiatry 2001; 62: 4-12.

[19] Feinstein AR. The pre-therapeutic classification of co-morbidity in chronic disease. J Chron Dis 1970; 23: 455-68.

[20] Maj M. "Psychiatric comorbidity": an artefact of current diagnostic systems? Br J Psychiatry 2005; 186: 182-4.

[21] Andrews G. Classification of neurotic disorders. J R Soc Med 1990; 83: 606-7. 
[22] Kessler RC, Keller MB, Wittchen HU. The epidemiology of generalized anxiety disorder. Psychiatr Clin North Am 2001; 24: 19-39.

[23] Wittchen HU, Zhao S, Kessler RC, Eaton WW. DSM-III-R generalized anxiety disorder in the National Comorbidity Survey. Arch Gen Psychiatry 1994; 51: 355-64.

[24] Wittchen HU, Kessler RC, Beesdo K, Krause P, Hofler M, Hoyer J. Generalized anxiety and depression in primary care: prevalence, recognition, and management. J Clin Psychiatry 2002; 63: 24-34.

[25] Judd LL, Kessler RC, Paulus MP, Zeller PV, Wittchen HU, Kunovac JL. Comorbidity as a fundamental feature of generalized anxiety disorders: results from the National Comorbidity Study (NCS). Acta Psychiatr Scand Suppl 1998; 393: 6-11.

[26] Stein DJ. Comorbidity in generalized anxiety disorder: impact and implications. J Clin Psychiatry 2000; 62: 29-34.

[27] Nutt D, Argyropoulos S, Hood S, Potokar J. Generalized anxiety disorder: A comorbid disease. Neuropsychopharmacology 2006; 16: 109-18.

[28] Faravelli C, Abrardi L, Bartolozzi D, Cecchi C, Cosci F, D'Adamo D, Lo Iacono B, Ravaldi C, Scarpato MA, Truglia E, Rosi S. The Sesto Fiorentino study: background, methods and preliminary results. Lifetime prevalence of psychiatric disorders in an Italian community sample using clinical interviewers. Psychother Psychosom 2004; 73: 216-25.

[29] Olino TM, Klein DN, Lewinsohn PM, Rohde P, Seeley JR. Longitudinal associations between depressive and anxiety disorders: a comparison of two trait models. Psychol Med 2008; 38: 353-63.

[30] Andreasen NC. DSM and the death of phenomenology in America: an example of unintended consequences. Schizophr Bull 2007; 33: 108-12.

[31] Jansson L, Handest P, Nielsen J, Sæbye D, Parnas J. Exploring boundaries of schizophrenia: a comparison of ICD-10 with other diagnostic systems in first-admitted patients. World Psychiatry. 2002; 1(2): 109-14.

[32] Jakobsen KD, Frederiksen JN, Parnas J, Werge T. Diagnostic agreement of schizophrenia spectrum disorders among chronic patients with functional psychoses. Psychopathology. 2006; 39(6): 269-76.

[33] Andreasen NC, Flaum M, Schultz S, Duzyurek S, Miller D. Diagnosis, methodology and subtypes of schizophrenia. Neuropsychobiology. 1997; 35(2): 61-3.

[34] Peralta V, Cuesta MJ. Exploring the borders of the schizoaffective spectrum: a categorical and dimensional approach. J Affect Disord. 2008; 108(1-2): 71-86

[35] Peralta V, Cuesta MJ. A dimensional and categorical architecture for the classification of psychotic disorders. World Psychiatry. 2007; 6(2): 100-1.

[36] Van Praag HM. Nosologomania: a disorder of psychiatry. World J Biol Psychiatry 2000; 1: 151-8

[37] Biondi M, Picardi A, Pasquini M, Gaetano P, Pancheri P. Dimensional psychopathology of depression: detection of an 'activation' dimension in unipolar depressed outpatients. J Affect Disord. 2005; 84(2-3): 133-9.

[38] Pancheri P, Picardi A, Pasquini M, Gaetano P, Biondi M. Psychopathological dimensions of depression: a factor study of the 17item Hamilton depression rating scale in unipolar depressed outpatients. J Affect Disord. 2002; 68(1): 41-7.

[39] Fava GA, Ruini C, Rafanelli C. Psychometric theory is an obstacle to the progress of clinical research. Psychother Psychosom. 2004; 73(3): 145-8

[40] Maj M. Is it possible to explain complex mental disorders at the biological level? World Psychiatry 2011; 10: 1 .

[41] Van Praag HM. Biological psychiatry: still marching forward in a dead end. World Psychiatry 2010; 9: 164-5.

(C) Faravelli et al.; Licensee Bentham Open.

This is an open access article licensed under the terms of the Creative Commons Attribution Non-Commercial License (http://creativecommons.org/licenses/by-nc/3.0/) which permits unrestricted, non-commercial use, distribution and reproduction in any medium, provided the work is properly cited. 